\title{
Períodos de Interferência de Plantas Daninhas na Cultura do SORGO ${ }^{1}$
}

\author{
Weed Interference Periods in Sorghum Crop
}

RODRIGUES, A.C.P. ${ }^{2}$, COSTA, N.V. ${ }^{3}$, CARDOSO, L.A. ${ }^{2}$, CAMPOS, C.F. ${ }^{4}$ e MARTINS, D. ${ }^{5}$

\begin{abstract}
RESUMO - Objetivou-se com este trabalho estimar os períodos de interferência das plantas daninhas na cultura do sorgo granífero BRS 310. O experimento foi realizado no municipio de Botucatu/SP, em delineamento experimental de blocos ao acaso, com quatro repetições. Os tratamentos constituíram-se de oito periodos de controle, nos quais a cultura foi mantida livre da comunidade de plantas daninhas, e de oito períodos de convivência, nos quais a cultura foi mantida na presença da comunidade infestante. Os períodos foram: $7,14,21,28$, 35, 42, 49 e 56 dias após a semeadura (DAS), além de uma testemunha mantida livre da interferência das plantas daninhas e outra mantida na presença destas. Foram identificadas 11 famílias e 17 espécies de plantas daninhas, destacando-se as famílias Asteraceae e Poaceae, com o maior número de espécies. Para determinação dos periodos de interferência, os dados de produtividade de grãos, comprimento da panícula e massa seca da parte aérea das plantas de sorgo obtidos foram ajustados ao modelo de regressão não linear: $y=a /\left[1+(x / b)^{c}\right]$. Considerando como aceitável perda de $5 \%$ para a produtividade de grãos, o comprimento da panícula e a massa seca da parte aérea das plantas de sorgo, determinou-se o período anterior à interferência (PAI) de 42, 72 e 15 DAS e o período total de prevenção à interferência (PTPI) de 26, 17 e 12 DAS, respectivamente. Não houve período crítico de prevenção da interferência (PCPI) para os parâmetros avaliados.
\end{abstract}

Palavras-chave: Sorghum bicolor, PAI, PTPI, competição.

ABSTRACT - The aim of this work was to estimate weed control periods and weed coexistence periods in sorghum 'BRS 310' crop. The experiment was carried out in Botucatu, São Paulo, Brazil. The experimental design was a randomized complete block with four replications and the treatments consisted of eight control periods, in which the crop was maintained weed-free and of eight coexistence periods, in which the crop was maintained in the presence of the weeds. The periods were 7, 14, $21,28,35,42,49$, and 56 days after sowing (DAS), besides a weed-free control and a control maintained in the presence of weed. To determine the periods of interference, grain yield data, panicle length and dry mass of the aerial part of the sorghum plants obtained were fit to the nonlinear regression model $y=a /[1+(x / b) c]$. Eleven families and 17 species of weeds were identified, with the families Asteraceae and Poaceae presenting the largest number of species. Considering as acceptable a loss of 5\% of grain yield, panicle length and dry mass of the aerial part of the sorghum plants, it was possible to determine the period previous to weed interference (PPWI) of 42, 72 and 15 DAS and the total period of prevention of weed interference (TPPWI) of 26, 17 and 12 DAS, respectively. No critical period of weed interference prevention (CPWIP) was observed for the parameters evaluated.

Keywords: Sorghum bicolor, PPWI, TPPWI, competition

1 Recebido para publicação em 18.3.2009 e na forma revisada em 12.3.2010.

2 Doutorando em Agronomia, Dep. de Produção Vegetal da FCA/UNESP, Botucatu-SP, <andreiacpr@hotmail.com>; ${ }^{3}$ Professor Adjunto - UNIOESTE/CCA, Marechal Cândido Rondon-PR; ${ }^{4}$ Graduando em Agronomia do Dep. de Produção Vegetal da FCA/UNESP, Botucatu-SP; 5 Professor Adjunto - FCA/UNESP, Fazenda Lageado, Caixa Postal 237, 18603-970 Botucatu-SP.

Planta Daninha, Viçosa-MG, v. 28, n. 1, p. 23-31, 2010 


\section{INTRODUÇÃO}

A cultura do sorgo está sujeita a uma série de fatores que podem influenciar o seu desenvolvimento e produção. Entre estes, as plantas daninhas podem promover perdas na produtividade devido à competição por fatores limitados no meio (luz, nutrientes e água), dificultando assim a colheita, além de atuarem como hospedeiras de pragas e doenças e exercerem pressão de natureza alelopática (Pitelli, 1985).

O conhecimento da capacidade de interferência de plantas daninhas sobre as culturas é importante na tomada de decisão para realização do controle (Vidal et al., 2004). Vários fatores influenciam a intensidade de competição entre as plantas cultivadas e as plantas daninhas. Eles foram, originalmente, esquematizados por Bleasdale (1960), modificados por Blanco (1972) e, posteriormente, adaptados por Pitelli (1985); alguns se referem à comunidade infestante (composição específica, densidade e distribuição), outros são referentes à cultura (características da espécie ou variedade, espaçamento e densidade de plantio).

Nesse contexto, a densidade de plantas e a época e extensão do período crítico de interferência destacam-se em importância, uma vez que estarão diretamente envolvidos nas tomadas de decisão de controle das plantas daninhas, podendo esses fatores ser alterados pelas condições edáficas, climáticas e pelos tratos culturais (Pitelli, 1985; Locke et al., 2002).

Para implantação de programas de manejo integrado de plantas daninhas, é imprescindivel conhecer os períodos de interferência destas com as culturas. Também_é necessário o conhecimento para a previsão da emergência das plantas infestantes e do impacto destas sobre as culturas (Ciuberkis et al., 2007).

Conforme proposto por Pitelli \& Durigan (1984), o período em que a cultura pode permanecer em convivência com uma comunidade de plantas daninhas sem haver interferência negativa em sua produção final é denominado de PAI (Período Anterior à Interferência), e o período a partir do plantio em que a cultura deve permanecer livre da presença das plantas daninhas para que não ocorram perdas de produção é denominado PTPI (Período Total de Prevenção da Interferência). A partir do estudo desses dois períodos, pode-se determinar também o período em que efetivamente os métodos de controle devem ser realizados para minimizar as perdas de produtividade: o PCPI (Período Crítico de Prevenção da Interferência).

Dessa forma, objetivou-se com este trabalho estimar o periodo anterior à interferência (PAI), o período total de prevenção da interferência (PTPI) e o período crítico de prevenção da interferência (PCPI) das plantas daninhas na cultura do sorgo, cultivar BRS 310 .

\section{MATERIAL E MÉTODOS}

O experimento foi realizado no Núcleo de Pesquisas Avançadas em MatologiaNUPAM, pertencente ao Departamento de Produção Vegetal da Faculdade de Ciências Agronômicas-FCA/UNESP, campus de Botucatu/SP, no ano agrícola 2006/2007, em solo argiloso, classificado como Nitossolo Vermelho Estruturado (Embrapa, 1999).

O preparo do solo consistiu de duas arações, sendo uma com arado de aiveca e a outra com grade pesada, além de duas operações com grade niveladora. A adubação foi realizada com aplicação de $310 \mathrm{~kg} \mathrm{ha}^{-1}$ da fórmula NPK 4-14-8, que foram distribuídos na linha de semeadura, mais uma adubação de cobertura de $\mathrm{N}\left(50 \mathrm{~kg} \mathrm{ha}^{-1}\right)$ aos 30 DAS (dias após a semeadura). A semeadura do sorgo cultivar BRS 310 foi realizada em 23 / 10/2006, com espaçamento de $0,5 \mathrm{~m}$ entre linhas e com 15 sementes $\mathrm{m}^{-1}$. As unidades experimentais foram constituídas de seis linhas de $5 \mathrm{~m}$ de comprimento, sendo consideradas como área útil as quatro linhas centrais.

O delineamento experimental utilizado foi o de blocos ao acaso, com quatro repetições. Os tratamentos constituiram-se de dois fatores: período de controle e de convivência das plantas daninhas. No período de controle, a cultura foi mantida livre de plantas daninhas nos períodos de $0,7,14,21,28,35,42,49$ e 56 DAS; as plantas daninhas que emergiram após cada período não mais foram controladas. No período de convivência, a cultura foi mantida na presença das plantas daninhas nos 
mesmos períodos citados anteriormente e sem plantas daninhas até a colheita.

O controle das plantas daninhas no final de cada período de convivência e de controle foi realizado por meio de capina manual. Para caracterização e estudo fitossociológico da comunidade infestante, foi amostrada uma área de 0,5 x 0,5 m de forma aleatória ao final de cada período, por parcela. As plantas daninhas foram contadas e identificadas segundo família, espécie e nome vulgar.

A partir da contagem das espécies presentes, foram calculadas as seguintes variáveis fitossociológicas: densidade (D) e índice de valor de importância (IVI), calculados segundo a fórmula proposta por Mueller-Dombois \& Ellemberg (1974). No final de cada período de convivência, as plantas daninhas foram cortadas rente ao solo, identificadas, agrupadas em Magnoliopsida e Liliopsida, sendo submetidas à secagem em estufa de circulação forçada de ar a $65 \pm 2{ }^{\circ} \mathrm{C}$ até atingirem peso constante, quando se determinou a massa seca.

Os dados de produtividade de grãos, comprimento da panícula e massa seca da parte aérea das plantas de sorgo de cada tratamento (períodos de controle e de convivência) foram ajustados ao modelo de regressão não linear, utilizando a equação proposta por Kozlowski et al. (2002a), determinando-se o período de interferência das plantas daninhas. Os dados foram analisados por meio do programa SigmaStat 2.0, de acordo com a equação logística:

$$
y=\frac{a}{\left[1+(x / b)^{c}\right]}
$$

em que $\mathrm{y}=$ produtividade de grãos; $\mathrm{x}=$ dias após a emergência; $a$ = produção máxima obtida nos períodos de controle e de convivência; $b=$ período (dias) em que ocorreram $50 \%$ de redução na produtividade máxima; e c = declividade da curva.

Os periodos de interferência foram estimados tolerando-se perdas de $5 \%$ na produtividade, comprimento de panícula e massa seca da parte aérea das plantas de sorgo. A estimativa dos valores referentes às perdas correspondentes a $5 \%$ para cada parâmetro avaliado foi feita segundo método proposto por Kozlowski et al. (2002a), por meio da diferença mínima significativa (DMS), obtida após a comparação das médias dos tratamentos (períodos de controle e de convivência) pelo teste LSD $(\mathrm{p}<0,05)$.

Também foi determinada a porcentagem de redução da produtividade de grãos da cultura do sorgo, a qual, como os dados da massa seca da parte aérea das plantas daninhas, foi ajustada ao modelo de regressão não linear e polinomial.

\section{RESULTADOS E DISCUSSÃO}

A comunidade infestante presente na área experimental foi composta por 11 famílias e 17 espécies, destacando-se a classe Magnoliopsida, com $64,7 \%$ das espécies presentes na área. As famílias Asteraceae e Poaceae apresentaram o maior número de espécies, com quatro em cada uma (Tabela 1).

Verificou-se aos 7 DAS que a comunidade de plantas daninhas encontrava-se numa densidade de 142 e 245 planta $\mathrm{m}^{-2}$ na área experimental para os periodos de controle e de convivência, respectivamente (Figura 1). Contudo, de modo geral, houve aumento de cerca de $42,0 \%$ na população de plantas daninhas nos tratamentos relativos aos períodos de convivência em relação aos referentes aos periodos de controle. A população de plantas daninhas atingiu as maiores densidades a partir dos 14 DAS (196 plantas $\mathrm{m}^{-2}$ ) e aos 28 DAS (732 plantas $\mathrm{m}^{-2}$ ), para os períodos de controle e de convivência, respectivamente (Figura 1). Entretanto, no período de controle em que o manejo das plantas daninhas foi de pelo menos 28 DAS, houve reduções na emergência das plântulas do banco de sementes e, consequentemente, diminuição da densidade das plantas daninhas em torno de $56,9 \%$ na área, mantendo-se níveis baixos de reinfestações ao longo de todo o ciclo da cultura, em relação ao tratamento que conviveu com a comunidade de plantas daninhas.

Quanto aos periodos de convivência a partir dos 28 DAS, verificou-se decréscimo na densidade das plantas daninhas até o final do ciclo da cultura, provavelmente devido à competição intraespecífica e interespecífica 
Tabela 1 - Relação das espécies de plantas daninhas presentes na área experimental. Botucatu-SP, 2006/07

\begin{tabular}{|l|l|l|}
\hline \multicolumn{1}{|c|}{ Família } & \multicolumn{1}{|c|}{ Espécie } & \multicolumn{1}{|c|}{ Magnoliopsida } \\
\hline & \multicolumn{1}{|c|}{ Nome vulgar } \\
\hline Amaranthaceae & Amaranthus lividus L. & Caruru \\
\hline Asteraceae & Acanthospermum hispidum (Loef.) Kuntze & Carrapicho-rasteiro \\
\hline & Bidens pilosa L. & Picão-preto \\
\hline & Emilia sonchifolia L. DC. & Falsa-serralha \\
\hline & Galinsoga parviflora Cav. & Picão-branco \\
\hline Brassicaceae & Raphanus raphanistrum L. & Nabiça \\
\hline Euphorbiaceae & Euphorbia heterophylla & Amendoim-bravo \\
\hline Lamiaceae & Leonotis nepetifolia (L.) R. Br. & Cordão-de-frade \\
\hline Malvaceae & Sida sp. & Guanxuma \\
\hline Oxalidaceae & Oxalis latifolia L. & Trevo \\
\hline Portulacaceae & Portulaca oleracea L. & Beldroega \\
\hline & & \\
\hline Commelinaceae & Commelina benghalensis L. & Trapoeraba \\
\hline Cyperaceae & Cyperus esculentus L. & Tiririca \\
\hline Poaceae & Brachiaria plantaginea (Link) Hitchc. & Capim-marmelada \\
\hline & Cenchrus echinatus L. & Capim-carrapicho \\
\hline & Digitaria horizontalis Willd. & Capim-colchão \\
\hline & Eleusine indica (L.) Gaert. & Capim-pé-de-galinha \\
\hline
\end{tabular}

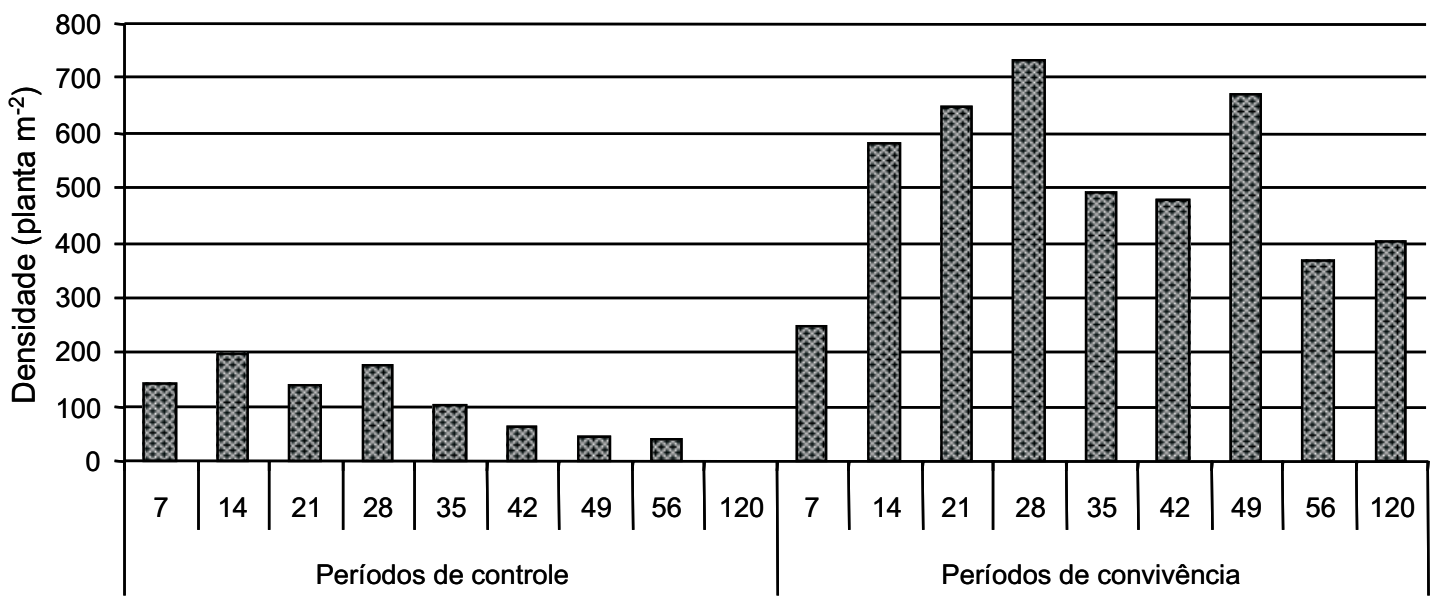

Dias Após a Semeadura

Figura 1 - Densidade de plantas daninhas no momento da colheita (120 DAS) para os períodos de controle e de convivência. Botucatu-SP, 2006/07.

que se estabeleceu na comunidade à medida que as espécies se desenvolveram (Figura 1).

Assim, esses dados evidenciam que a utilização de variedades ou de híbridos de sorgo que apresentam rápido desenvolvimento e fechamento das entrelinhas de plantio, de maneira que diminua a incidência de luz que atinge o solo, proporcionando um ambiente desfavorável para o crescimento e desenvolvimento de plantas daninhas, deve ser uma das metas dos melhoristas dessa cultura.

Na Figura 2 são apresentados o índice de valor de importância (IVI) das plantas daninhas em cada tratamento para os periodos de controle e de convivência. Apesar de as espécies da classe Liliopsida representarem apenas 
$35,3 \%$ do total das espécies presentes na área experimental, para os tratamentos referentes aos períodos de controle, estas demonstraram os maiores IVI, destacando-se Brachiaria plantaginea, Commelina benghalensis, Cenchrus echinatus e Eleusine indica. Entre as espécies da classe Magnoliopsida destacou-se Galinsoga parviflora (Tabela 1).

De maneira geral, para os períodos de controle, as espécies $B$. plantaginea $\mathrm{e}$ C. benghalensis foram as predominantes, apresentando em média 52,0 e $62,0 \%$ de IVI, respectivamente (Figura 2).

Verificou-se que a espécie $B$. plantaginea mostrou maior habilidade competitiva no período de convivência a partir dos 7 DAS, apresentando os maiores valores de IVI em relação aos dos demais espécies. Ressalta-se que, aos 56 e 120 DAS, as espécies $C$. echinatus e G. parviflora não foram identificadas, o que pode ser explicado pelo fato de o desenvolvimento da cultura e a predominância da espécie $B$. plantaginea terem exercido efeito supressivo sobre essas espécies.

Vários pesquisadores destacaram que as espécies de plantas daninhas identificadas neste trabalho foram importantes competidoras em lavouras de milho, soja, feijão e batata
(Kozlowski et al., 2002a,b; Vidal et al., 2004; Costa et al., 2008).

A produtividade de grãos, o comprimento de panícula e a massa seca da parte aérea das plantas de sorgo ajustaram-se à equação de regressão não linear para os períodos de controle e de convivência (Figuras 3, 5 e 6).

De acordo com os resultados, a cultura do sorgo (BRS 310) pode permanecer em convivência com a comunidade de plantas daninhas sem perdas significativas na produtividade de grãos por 42,04 dias após a semeadura $(\mathrm{PAI}=42 \mathrm{DAS})$ (Figura 3$)$. O período total de prevenção da interferência (PTPI) foi de 26,22 dias (PTPI = 26 DAS). Desse modo, pode-se verificar que o PAI foi maior que o PTPI - neste caso, não ocorreu o PCPI. Assim, segundo Pitelli \& Durigan (1984), quando esse fato ocorre, o controle das plantas daninhas em uma época é suficiente, desde que realizado entre o término do PAI e o término do PTPI, para que a cultura possa expressar seu potencial produtivo. Para essa condição podem-se utilizar capinas e/ou herbicidas pós-emergentes desprovidos de efeito residual; outra opção seria a utilização de herbicida pré-emergente com efeito residual que ultrapasse o PTPI (Carvalho \& Velini, 2001).

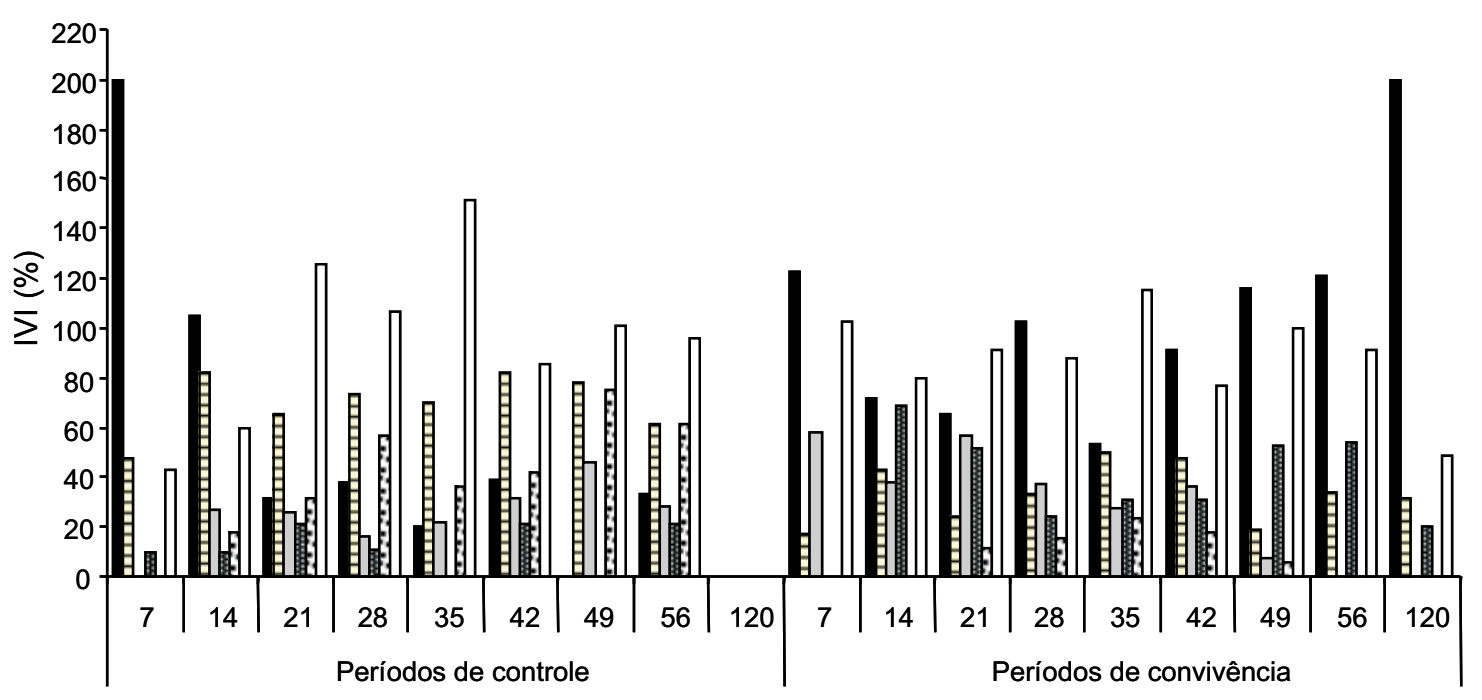

Dias Após a Semeadura

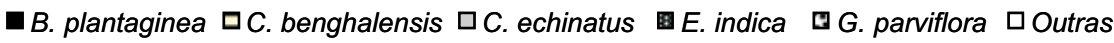

Figura 2 - Índice de valor de importância (IVI) das plantas daninhas para os períodos de controle e de convivência. Botucatu-SP, 2006/07. 


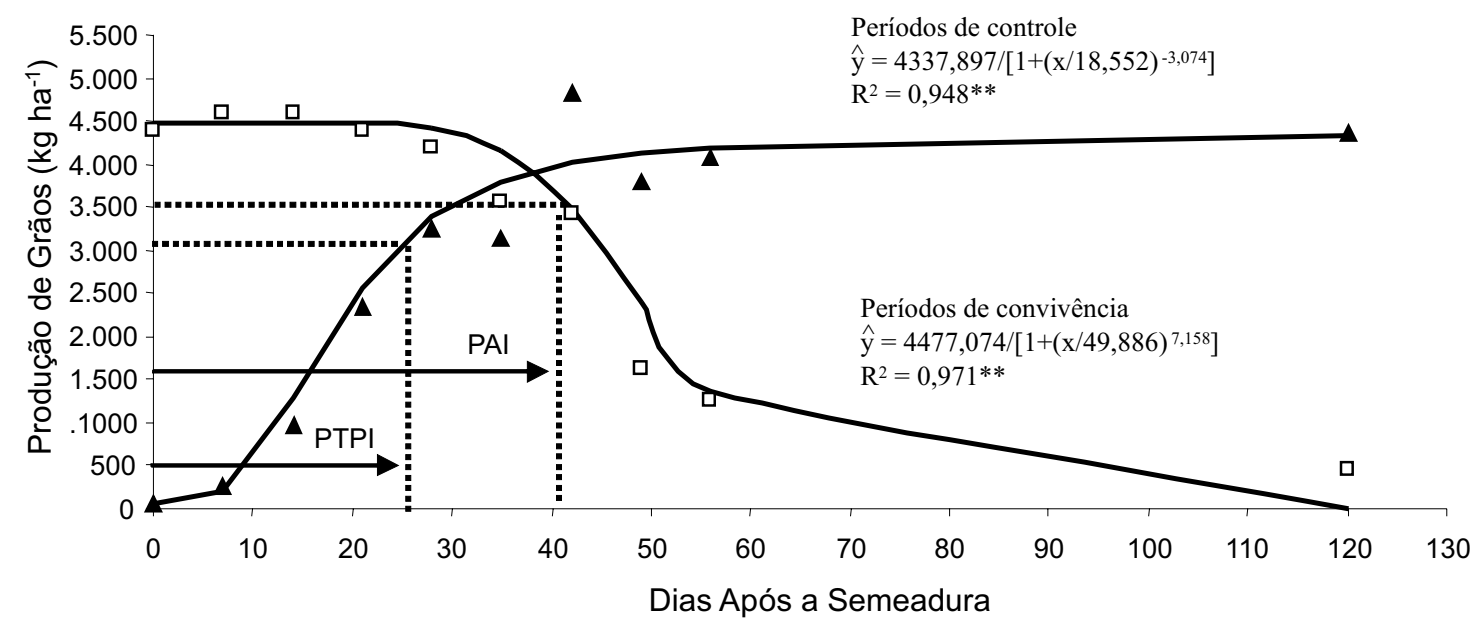

$\Delta$ Períodos de controle $\quad \square$ Períodos de convivência

Figura 3 - Produtividade de grãos da cultura do sorgo em função dos períodos de controle e de convivência com as plantas daninhas. Botucatu-SP, 2006/07.

Considerando o PAI de 42 DAS, verificouse redução na produtividade de grãos em torno de $52,4 \%$, enquanto para o PTPI de 26 DAS a redução foi de $41,7 \%$, em relação à produção da testemunha no limpo (Figura 4). Silva et al. (1986) observaram que, não havendo controle das plantas daninhas nas quatro primeiras semanas após a emergência do sorgo, pode ocorrer redução na produção de grãos da ordem de $35 \%$; sem a realização de controle essa redução pode chegar a $70 \%$. Neste trabalho, houve limitação de produtividade na ordem de $89,6 \%$ quando comparados os tratamentos sem e com interferência das plantas daninhas durante o ciclo da cultura (Figura 4).

Contudo, em algumas situações a presença de plantas daninhas convivendo com a cultura pode proporcionar aumentos na produtividade, como foi observado para os períodos de convivência de 7 e 14 DAS (Figura 3), que evidenciaram aumentos da produção de grãos na média de $5,4 \%$, em relação à testemunha totalmente no limpo. Resultados semelhantes também foram verificados por Souza (1992), que observou aumento de 36\% na produtividade da cevada quando na presença da comunidade de plantas daninhas durante periodos de estresse hídrico.

Para os dados de comprimento de panícula determinou-se o PAI de 71,60 DAS, e o PTPI do período foi de 17,30 DAS. Já para os dados de massa seca da parte aérea das plantas de sorgo, o PAI e o PTPI foram de 15,33 e 11,76 DAS, respectivamente (Figuras 5 e 6). Ressalta-se que, conforme verificado para os valores de produção de grãos de sorgo (Figura 3), o PAI foi maior que o PTPI, não se observando PCPI em ambos os parâmetros avaliados.

Entretanto, observou-se que a interferência das plantas daninhas em relação ao comprimento de panículas e a massa seca da parte aérea das plantas de sorgo colaboraram para a redução da produção de grãos, uma vez que, comparando-se as testemunhas sempre no limpo e sempre no sujo, verificaram-se reduções em torno de 26,3 e 41,8\%, respectivamente. Destaca-se que, entre os componentes de produção avaliados, a massa seca da parte aérea das plantas de sorgo foi o mais sensivel à interferência das plantas daninhas, visto que apresentou os períodos de interferência mais curtos. Alguns conceitos da fisiologia vegetal preveem maior investimento em estatura (estiolamento) das plantas em competição por luz - isso poderia interferir na produção da massa seca e reduzir a produtividade.

Observou-se para os períodos de controle que a massa seca das plantas daninhas Magnoliopsida representou 89,8\% do total, enquanto as Liliopsida representaram apenas 10,2\% (Figura 7 ). 


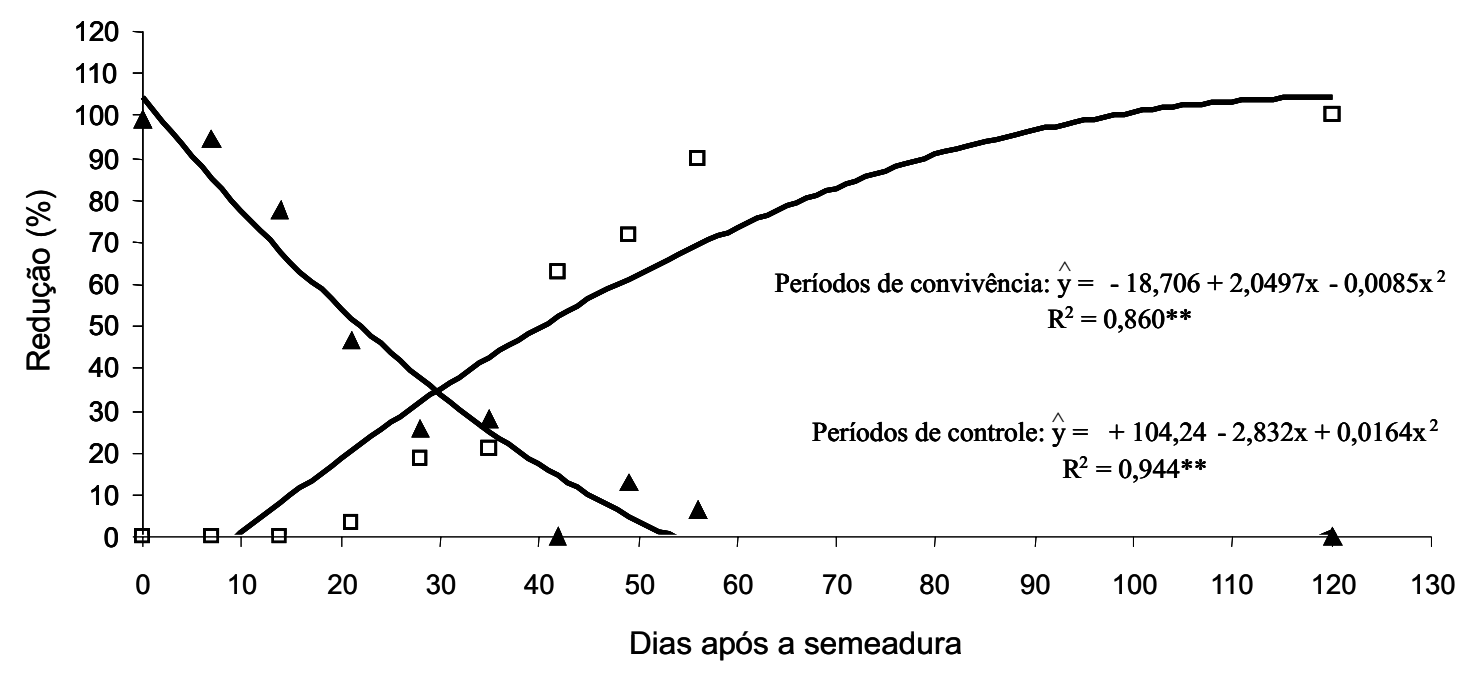

Figura 4 - Porcentagem de redução da produtividade de grãos da cultura do sorgo em função dos períodos de controle e de convivência com as plantas daninhas. Botucatu-SP, 2006/07.

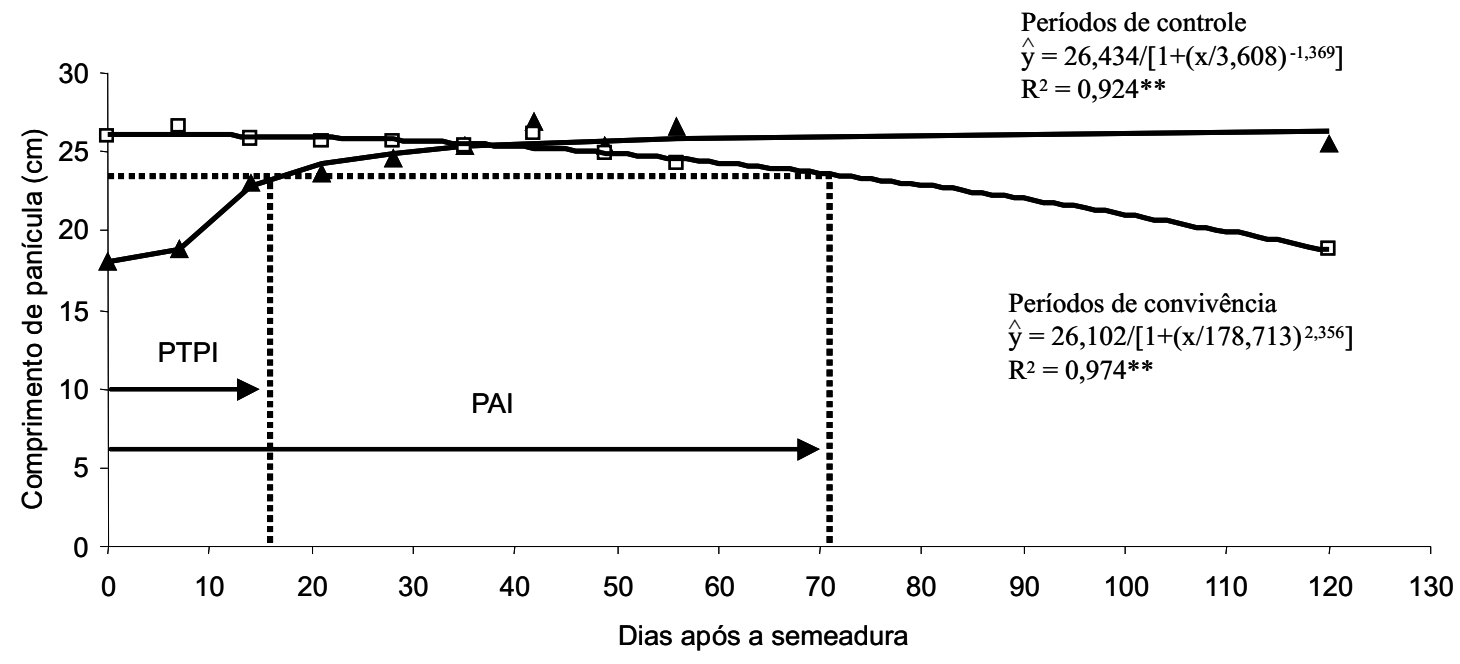

\section{A Períodos de controle $\square$ Períodos de convivência}

Figura 5 - Comprimento de panículas de sorgo avaliado aos 120 DAS em função dos períodos de controle e de convivência com as plantas daninhas. Botucatu-SP, 2006/07.

Os dados de massa seca das plantas daninhas durante os períodos de controle não se ajustaram aos modelos de regressão (Figura 7A). Quanto aos períodos de convivência, constatou-se incremento na massa seca das plantas daninhas a partir dos 14 DAS até o final do ciclo da cultura, sendo mais expressivo no período de 28 a 49 DAS (Figura 7B). Neste período ocorreu maior predominância das espécies de Liliopsida, com 75,4\% a partir dos 14 DAS (Figura 7B).
Constatou-se que o efeito da competição entre as plantas daninhas com a cultura do sorgo pode determinar diferentes períodos de interferência, dependendo do componente de produção a ser considerado (Tabela 2).

Dessa forma, considerando a perda de 5\% para a produtividade de grãos, o comprimento da panícula e a massa seca da parte aérea das plantas de sorgo como aceitáveis, determinouse o período anterior à interferência (PAI) de 42,72 e 15 DAS, e o período total de prevenção 


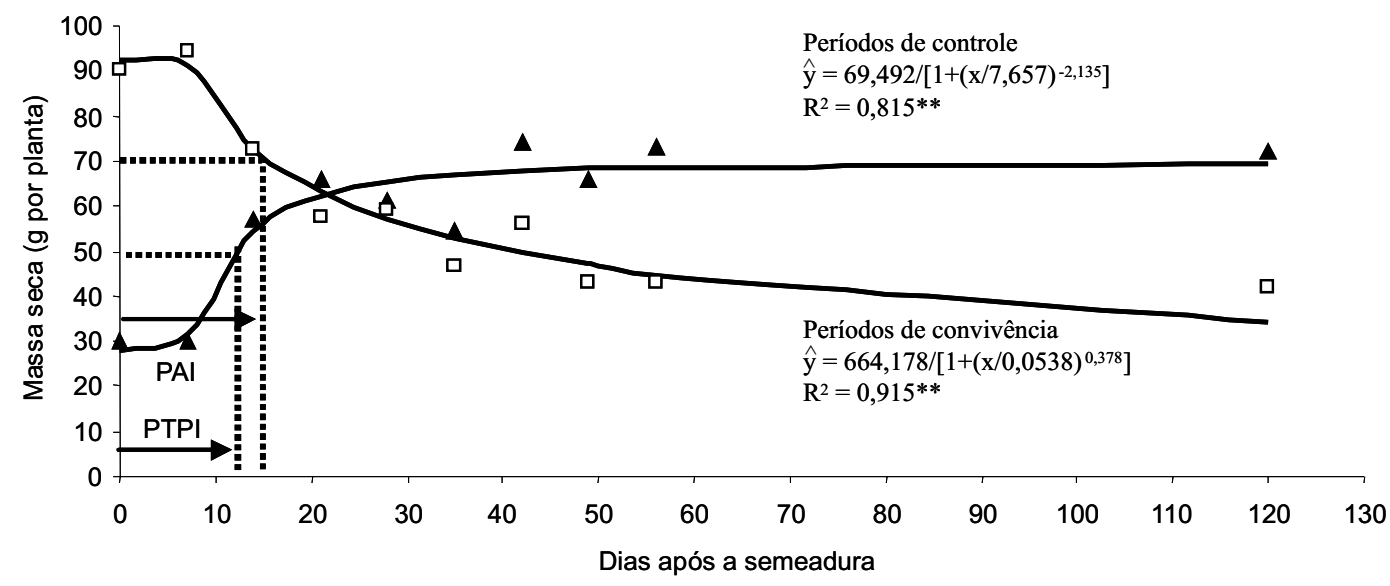

A Períodos de controle $\square$ Períodos de convivência

Figura 6 - Massa seca da parte aérea das plantas de sorgo em função dos períodos de controle e de convivência com as plantas daninhas. Botucatu-SP, 2006/07.
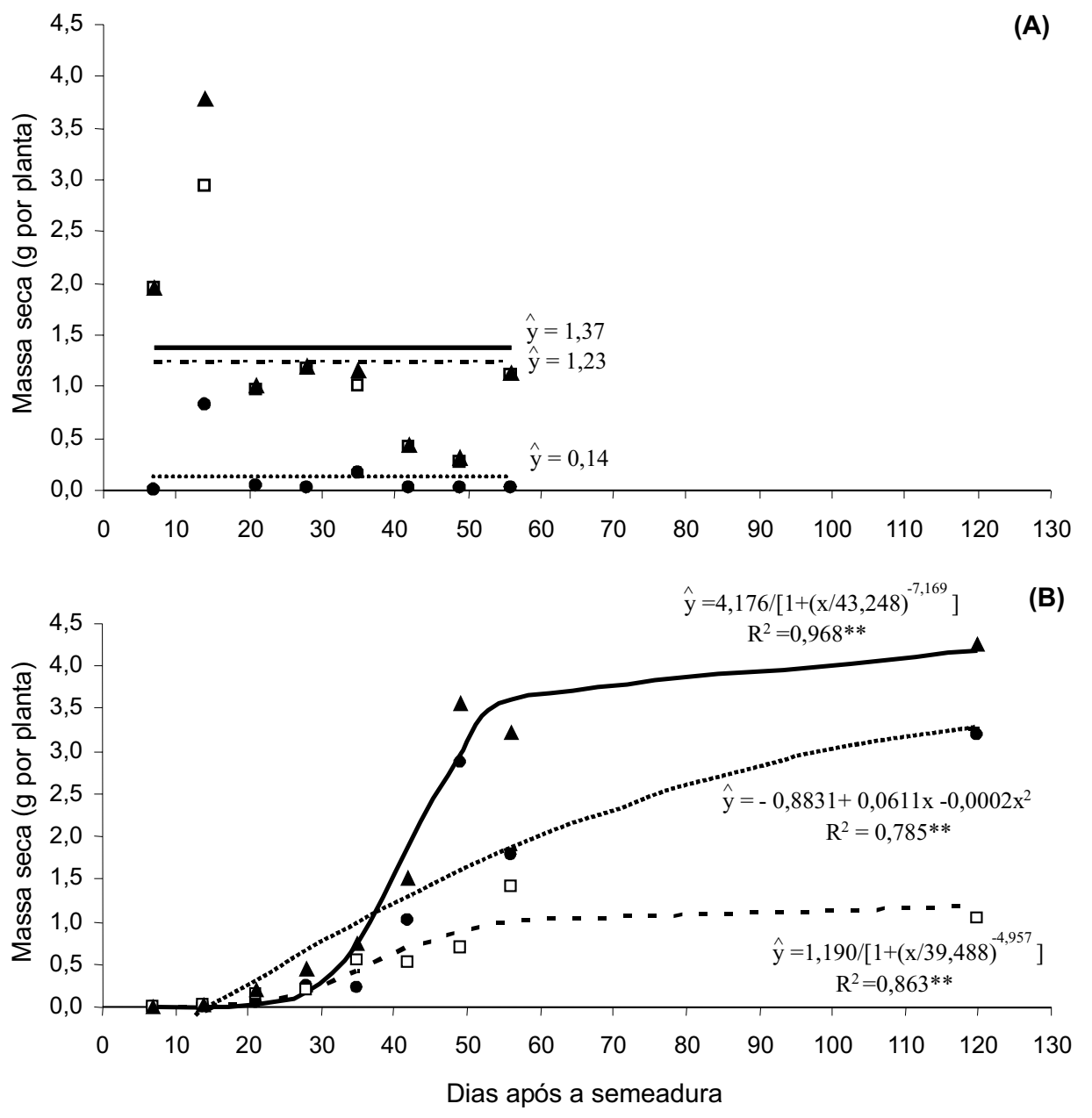

- Liliopsida $\square$ Magnoliopsida $\Delta$ Total

Figura 7 - Massa seca das plantas daninhas Magnoliopsida, Liliopsida e total, avaliada aos 120 DAS, em função dos períodos de controle (A) e de convivência (B) com as plantas daninhas. Botucatu-SP, 2006/07. 
Tabela 2 - Períodos de interferência das plantas daninhas na cultura do sorgo de acordo com os componentes de produção. Botucatu-SP, 2006/07

\begin{tabular}{|l|c|c|c|}
\hline \multirow{2}{*}{\multicolumn{1}{|c|}{ Parâmetro }} & \multicolumn{3}{|c|}{ Período de interferência } \\
\cline { 2 - 4 } & PAI & PTPI & PCPI \\
\hline Produtividade de grãos & 42 & 26 & --- \\
\hline Comprimento de panícula & 72 & 17 & --- \\
\hline Massa seca da parte aérea & 15 & 12 & --- \\
\hline
\end{tabular}

à interferência (PTPI), de 26, 17 e 12 DAS, respectivamente. Não houve periodo crítico de prevenção da interferência (PCPI) para nenhum dos parâmetros avaliados (PAI > PTPI).

\section{LITERATURA CITADA}

BLANCO, H. G. A importância dos estudos ecológicos nos programas de controle das plantas daninhas. O Biológico, v. 38, n. 10 , p. $343-50,1972$

BLEASDALE, J. K. Studies on plant competition. In: HARPER, J. L. (Ed.). The biology of weeds. Oxford: Blackweek Scientific, 1960. p. 133-142.

CIUBERKIS, S. et al. Effect of weed emergence time and intervals of weed and crop competition on potato yield.

Weed Technol., v. 21, n. 1, p. 213-218, 2007.

COSTA, N. V. et al. Períodos de interferência de uma comunidade de plantas daninhas na cultura da batata. Planta Daninha, v. 26, n. 1, p. 83-91, 2008.

\section{EMPRESA BRASILEIRA DE PESQUISA}

AGROPECUÁRIA - EMBRAPA. Centro Nacional de Pesquisa de Solos. Sistema brasileiro de classificação de solos. Brasília: Embrapa Produção de Informação; Rio de Janeiro: Embrapa Solos, 1999. 412 p.
CARVALHO, F. T.; VELINI, E. D. Períodos de interferência de plantas daninhas na cultura da soja. I - Cultivar IAC-11. Planta Daninha, v. 19, n. 3, p. 317-322, 2001.

KOZLOWSKI, L. A. et al. Período crítico de interferência das plantas daninhas na cultura do feijoeiro-comum em sistema de semeadura direta. Planta Daninha, v. 20, n. 2, p. 213-220, 2002a.

KOZLOWSKI, L. A. Período crítico de interferência das plantas daninhas na cultura do milho baseado na fenologia da cultura. Planta Daninha, v. 20, n. 3, p. 365-372, 2002b.

LOCKE, M. A.; REDDY, K. N.; ZABLOTOWICZ, R. M. Weed management in conservation crop production systems. Weed Biol. Manag., v. 2, n. 1, p. 123-132, 2002.

MUELlER-DOMBOIS, D.; ELLENBERG, H. Aims and methods of vegetation ecology. New York: John Wiley \& Sons, 1974. 547 p.

PITELLI, R. A. Interferência de plantas daninhas em culturas agrícolas. Inf. Agropec., v. 11, n. 129, p. 16-17, 1985.

PITELLI, R. A.; DURIGAN, J. C. Terminologia para períodos de controle e de convivência de plantas daninhas em culturas anuais e bianuais. In: CONGRESSO BRASILEIRO DE HERBICIDAS E PLANTAS DANINHAS, 15., 1984, Belo Horizonte. Resumos... Piracicaba: 1984. p. 37.

SILVA, J. B.; PASSINI, T.; VIANA, A. C. Controle de plantas daninhas na cultura do sorgo. Inf. Agropec., v. 12, n. 144, p. $43-45,1986$.

SOUZA, J. R. P. Efeito de diferentes períodos de controle da comunidade infestante sobre o desenvolvimento e produtividade da cultura da cevada (Hordeum vulgare L.) 1992. 86 f. Dissertação (Mestrado em Agronomia) Universidade Estadual de São Paulo, Botucatu, 1992.

VIDAL, R. A. et al. Nível de dano econômico de Brachiaria plantaginea na cultura de milho irrigado. Planta Daninha, v. 22, n. 1, p. 63-69, 2004. 